\title{
PENGARUH PEMBERIAN KOMPRES BLUE ICE TERHADAP SKALA NYERI PADA BAYI YANG TELAH MENDAPATKAN IMUNISASI HEPATITIS B-0
}

\author{
${ }^{1}$ Denni Fransiska, ${ }^{2}$ Helena Marpaung \\ ${ }^{1,2}$ Staf Dosen Akademi Keperawatan Kebonjati Bandung \\ E-mail : denni.fransiska75@gmail.com
}

\begin{abstract}
Abstrak
Tujuan penelitian untuk menganalisis pengaruh kompres blue ice terhadap skala nyeri pada bayi yang mendapatkan imunisasi Hepatitis B-0 di ruang Cempaka RS. Kebonjati Bandung. Desain yang digunakan dalam penelitian ini adalah true experimental design dengan bentuk post test only control group design. Sampel berjumlah 18 bayi pada masing-masing kelompok intervensi dan kontrol. Observasi skala nyeri menggunakan Neonatal Infant Pain Scale (NIPS). Analisa data menggunakan analisa univariat dan bivariat menggunakan uji Mann Whitney. Hasil uji diperoleh score nyeri sesudah imunisasi pada kelompok intervensi 1 , sedangkan score nyeri pada kelompok kontrol 5. Hasil uji statistik Mann Whitney didapatkan nilai p-value 0,00 dengan $\alpha<0,05$, dengan demikian Ho ditolak artinya kompres blue ice berpengaruh terhadap skala nyeri pada bayi yang mendapatkan imunisasi Hepatitis B-0. Hasil penelitian ini dapat dijadikan suatu kebijakan dan protap sebagai prosedur dalam mengurangi nyeri pada bayi yang di imunisasi.
\end{abstract}

Kata Kunci : Imunisasi, nyeri, kompres blue ice

\begin{abstract}
The purpose of the study to analyze the effect of giving blue ice compress to pain scale on infants who has get Hepatitis B-0 immunization in Cempaka Room at Kebonjati Hospital, Bandung. The design this research is true experimental with post-test only control group design. Samples were 18 infants in each group of intervention and control. Observation using Neonatal Infant Pain Scale (NIPS). Analysis of data using univariate and bivariate analysis of the Mann Whitney test. Test results obtained after immunization pain score in intervention group 1, where as the pain score in the control group 5. Statistical test results obtained p-value 0.00, thus Ho is rejected it means blue ice compress effect on the pain scale in infants who have received Hepatitis $B-0$ immunization. The results of this study can be use as a policy and standard operating procedure as reducing pain in infants would be immunization.
\end{abstract}

Keywords: Blue ice compress, immunization, pain

\section{PENDAHULUAN}

Imunisasi adalah pemberian kekebalan tubuh terhadap suatu penyakit dengan memasukkan sesuatu ke dalam tubuh agar tubuh tahan terhadap penyakit. Imunisasi berasal dari kata imun yang berarti kebal atau resisten. Imunisasi memang penting untuk membangun pertahanan tubuh bayi, dengan imunisasi diharapkan anak terhindar dari berbagai penyakit yang membahayakan jiwanya. Seiring dengan cakupan imunisasi yang tinggi maka penggunaan vaksin juga meningkat, dan akibatnya kejadian yang berhubungan dengan imunisasi juga meningkat. Reaksi suntikan terjadi akibat trauma tusuk jarum suntik baik langsung maupun tidak langsung. Reaksi suntikan langsung berupa nyeri/sakit, bengkak dan kemerahan pada daerah suntikan, sedangkan reaksi suntikan tidak langsung berupa rasa takut, mual, pusing, atau bahkan sampai sinkop (Akib \& Purwanti dalam Ranuh et al, 2011).

Respon nyeri yang timbul pada setiap orang berbeda beda, hal tersebut dipengaruhi oleh usia, jenis kelamin, kultur, makna nyeri, perhatian, ansietas, keletihan, pengalaman masa lalu, pola koping, serta dukungan keluarga dan sosial (Potter \& Perry, 2006). Nyeri yang berlangsung dalam waktu yang lama dapat menyebabkan penurunan saturasi oksigen, peningkatan denyut jantung, peningkatan tekanan intra kranial sehingga 
meningkatkan resiko terjadinya perdarahan intraventrikuler pada bayi prematur (Kenner \& McGart, 2004).

Pengkajian nyeri pada neonatus umumnya menggunakan data berdasarkan perubahan fisiologis dan observasi perilaku (Hockenberry \& Wilson, 2009). Skala pengukuran nyeri yang direkomendasikan untuk anak dibawah usia satu tahun adalah NIPS (Neonatal Infant Pain Scale). Skala ini terdiri dari 6 variabel penilaian meliputi: ekspresi wajah (0-1), tidur (0-1), menangis (0$2)$, kaki (0-1), pola pernafasan (0-1) dan kepekaan terhadap rangsang (0-1). Perhitungan skala nyeri NIPS dikategorikan menjadi tidak nyeri dan nyeri dengan total skor 7. Hasil penilaian dikatakan tidak nyeri jika total skor $\leq 3$ dan dikategorikan nyeri bila total skor > 3 (Malarvizhi et al., 2012).

Beberapa intervensi untuk mengurangi dan mengatasi nyeri yang timbul terkait imunisasi telah dipelajari dan dilaporkan dalam beberapa literatur, seperti: intervensi lingkungan, pembedongan, non nutrive sucking (NNS), skin to skin contact, breastfeeding, pemberian glukosa/sukrosa, multisensory stimulation (seperti pijitan, suara, kontak mata dan wangi parfum), anastesi topikal, dan stimulasi kutaneus (Neil etal, 2007; Buonocore \& Bellieni, 2008; Dilli, 2009; Taddio, 2010; Esfahani, 2013; Abuelkheir, 2014).

Dari hasil studi pendahuluan, didapatkan data; tindakan yang dilakukan perawat sebelum bayi di imunisasi adalah bayi diletakkan di meja pemeriksaan, tidak ada satupun bayi yang digendong orang tua pada saat di imunisasi dan tidak ada suatu tindakan yang dilakukan perawat untuk mengurangi reaksi nyeri pada bayi. Reaksi yang muncul pada bayi saat di imunisasi adalah menangis dan meronta saat bayi di imunisasi. Berdasarkan fenomena diatas peneliti tertarik untuk melakukan penelitian terkait intervensi pemberian kompres es untuk mengatasi nyeri pada bayi yang di imunisasi.

\section{METODE PENELITIAN}

Desain yang digunakan dalam penelitian ini adalah true experimental design dengan bentuk post test only control group design. Post test only control group design berarti bahwa pengukuran hanya dilakukan setelah selesai intervensi. Sampel dipilih berdasarkan kriteria yang telah ditetapkan sebelumnya yaitu bayi baru lahir sampai berusia 7 hari yang mendapatkan imunisasi Hepatitis B 0 (HB 0), di ruang Cempaka RS. Kebonjati Bandung dengan jumlah sampel 18 untuk setiap kelompok, sehingga jumlah sampel keseluruhan adalah 36 sampel.

Instrumen yang digunakan dalam penelitian ini berupa Blue ice, termometer air, jam tangan, kuesioner karakteristik responden dan lembar observasi skala NIPS. Lembar observasi skala NIPS terdiri dari 6 (enam) parameter yaitu: ekspresi wajah, tangisan, pola nafas, gerakan lengan, gerakan tungkai dan status terjaga. Instrumen NIPS ini telah banyak digunakan pada neonatus dan telah diiuji reliabilitasnya dengan nilai internal consistency dan cronbach's a 0,95, 0,87 dan 0,88 untuk skor sebelum, selama dan setelah prosedur (Hockenberry \& Wilson, 2009; Malarvizhi, 2012), sehingga peneliti tidak melakukan uji validitas dan reabilitas.

Pengolahan data dilakukan dengan cara editing, coding, processing dan cleaning. Analisis data dilakukan setelah proses pengolahan data dilakukan dengan menggunakan analisis univariat dan analisis bivariat. Uji normalitas data dalam penelitian ini menggunakan uji Shapiro-Wilk dengan derajat kemaknaan 95\% atau $\alpha=0,05$ (Dahlan, 2011). Hasil uji normalitas didapatkan data pada kelompok kontrol dan kelompok intervensi berdistribusi tidak normal dimana $p$-value $<0,05$, sehingga untuk menguji perbedaan skor nilai nyeri pada kelompok intervensi dan kelompok kontrol menggunakan uji non parametrik dengan uji Mann Withney.

Penelitian ini dilakukan setelah mendapat persetujuan dari insitusi pendidikan yaitu Program Pasca Sarjana Stikes Achmad Yani Cimahi dan izin pimpinan Rumah Sakit Kebonjati Bandung. Uji kaji etik (Ethical Clearence) peneliti didapat dari Stikes Ahmad Yani 
HASIL PENELITIAN

Karakteristik Responden Berdasarkan Usia dan Jenis Kelamin

Tabel 1. Distribusi frekuensi karakteristik responden berdasarkan usia dan jenis kelamin pada kelompok intervensi dan kontrol.

\begin{tabular}{ccccccc}
\hline Variabel & \multicolumn{2}{c}{ Kelompok } & \multicolumn{2}{c}{ Kelompok } & \multicolumn{2}{c}{$\begin{array}{c}\text { Jumlah } \\
(\mathrm{n}=36)\end{array}$} \\
\hline Usia (hari) & $\mathrm{F}$ & $\%$ & $\mathrm{f}$ & $\%$ & $\mathrm{f}$ & $\%$ \\
\hline 0 & 12 & 66,7 & 13 & 72,2 & 25 & 69,4 \\
\hline 1 & 6 & 33,3 & 2 & 11,1 & 8 & 22,2 \\
\hline 2 & 0 & 0 & 1 & 5,6 & 1 & 2,8 \\
\hline 3 & 0 & 0 & 1 & 5,6 & 1 & 2,8 \\
\hline 6 & 0 & 0 & 1 & 5,6 & 1 & 2,8 \\
\hline Total & 18 & 100 & 18 & 100 & 36 & 100 \\
\hline Jenis Kelamin & & & & & & \\
\hline Paki-Laki & 11 & 61,1 & 8 & 44,4 & 19 & 52,8 \\
\hline Total & 7 & 38,9 & 10 & 55,6 & 17 & 47,2 \\
\hline
\end{tabular}

Pada tabel 1 di atas menunjukan bahwa presentasi karakteristik bayi pada kelompok intervensi terbesar pada usia 0 hari $(66,7 \%)$. Pada kelompok kontrol diperoleh presentasi karakteristik bayi berdasarkan usia terbesar juga pada usia 0 hari $(72,2 \%)$. Hasil estimasi disimpulkan secara keseluruhan pada kelompok intervensi dan kontrol bahwa 69,4\% responden yang menerima imunisasi Hepatitis B 0 berusia 0 hari. Berdasarkan jenis kelamin, tabel 1 menunjukkan bahwa pada kelompok intervensi sebagian besar berjenis kelamin laki-laki yaitu 11 bayi $(61,1 \%)$. Pada kelompok kontrol sebagian besar berjenis kelamin perempuan yaitu sebanyak 10 bayi $(55,6 \%)$.

\section{Score Nyeri Sesudah Imunisasi}

Tabel 2. Score nyeri sesudah imunisasi Hepatitis B 0 pada kelompok intervensi dan kelompok kontrol

\begin{tabular}{cccc}
\hline Kelompok & Median & Min-Mak & SD \\
\hline Intervensi & 1 & $0-5$ & 1,59 \\
\hline Kontrol & 5 & $1-7$ & 1,25 \\
\hline
\end{tabular}

Tabel 2. menunjukkan bahwa intensitas nyeri pada kelompok intervensi dengan score median 1 (satu), score terendah 0 (nol) dan score tertinggi 5 (lima). Intensitas nyeri pada kelompok kontrol dengan score median 5 (lima), score terendah 1 (satu) dan score tertinggi 7 (tujuh).

\section{Pengaruh Kompres Blue Ice Terhadap Skala Nyeri Pada Bayi YangTelah Mendapatkan Imunisasi Hepatitis B 0}

Tabel 3 di atas menunjukkan bahwa pada kelompok intervensi lebih banyak mengalami tidak nyeri sebanyak 14 (77,8\%) dibandingkan dengan kelompok kontrol yang mengalami tidak nyeri sebanyak 2 bayi $(11,1 \%)$. Berdasarkan hasil uji statistik menggunakan uji Mann Whitney didapatkan p-value $0,00(\alpha<0,05)$, dengan demikian Ho ditolak artinya kompres blue ice berpengaruh terhadap skala nyeri pada bayi yang telah mendapatkan imunisasi Hepatitis B 0 . 
Tabel 3. Pengaruh kompres blue ice terhadap skala nyeri pada bayi yang telah mendapatkan imunisasi Hepatitis B 0

\begin{tabular}{cccccccc}
\hline \multirow{2}{*}{$\begin{array}{c}\text { Kelompok } \\
\text { Responden }\end{array}$} & \multicolumn{4}{c}{ Skala Nyeri } & \multicolumn{2}{c}{ Jumlah } & \multirow{2}{*}{ p-value } \\
\cline { 2 - 6 } & \multicolumn{2}{c}{ Tidak Nyeri } & \multicolumn{2}{c}{ Nyeri } & & \\
\cline { 2 - 7 } & $\mathrm{f}$ & $\%$ & $\mathrm{f}$ & $\%$ & $\mathrm{~F}$ & $\%$ & \\
\hline Intervensi & 14 & 77,8 & 4 & 22,2 & 18 & 100 & \\
\hline Kontrol & 2 & 11,1 & 16 & 88,9 & 18 & 100 & 0,00 \\
\hline Total & 16 & 44,4 & 20 & 55,6 & 36 & 100 & \\
\hline
\end{tabular}

Tabel 3. di atas menunjukkan bahwa pada kelompok intervensi lebih banyak mengalami tidak nyeri sebanyak 14 (77,8\%) dibandingkan dengan kelompok kontrol yang mengalami tidak nyeri sebanyak 2 bayi $(11,1 \%)$. Berdasarkan hasil uji statistik menggunakan uji Mann Whitney didapatkan p-value 0,00 $(\alpha<0,05)$, dengan demikian Ho ditolak artinya kompres blue ice berpengaruh terhadap skala nyeri pada bayi yang telah mendapatkan imunisasi Hepatitis B 0 .

\section{PEMBAHASAN}

\section{Karakteristik Responden Berdasarkan Usia dan Jenis Kelamin}

Sebagian besar responden $(69,4 \%)$ mendapatkan imunisasi hepatitis B 0 pada usia 0 hari. Berdasarkan jenis kelamin dari total seluruh responden sebagian besar bayi baru lahir yang mendapatkan imunisasi Hepatitis B 0 sebagian besar berjenis kelamin laki-laki $(52,8 \%)$. Data tersebut menunjukkan bahwa sebagian besar bayi yang lahir di RS. Kebonjati dan mendapatkan imunisasi hepatitis B 0 kurang dari 1 minggu dan berjenis kelamin laki-laki .

Program imunisasi di Indonesia terdiri dari dua jenis, yaitu imunisasi wajib dan imunisasi tambahan (Achmadi, 2006). Imunisasi wajib diberikan kepada bayi baru lahir sampai usia satu tahun. Imunisasi wajib yang pertama kali diberikan pada bayi baru lahir adalah Hepatitis B 0 . Berdasarkan rekomendasi WHO pada tahun 2006, program imunisasi khususnya imunisasi hepatitis B mengalami perubahan sebagai berikut: 1). imunisasi hepatitis B diberikan pertama kali pada bayi saat berusia 0-7 hari; 2). pemberian imunisasi hepatitis $B$ yang pertama kali bukan dinyatakan sebagai imunisasi hepatitis B-1, tetapi pemberian imunisasi hepatitis B-0; 3 ). pemberian imunisasi selanjutnya diberikan bersamaan dengan vaksin DPT yang disebut dengan "DPT Combo", diberikan pada bayi saat berusia 6 minggu. Imunisasi DPT Combo (DPT/HB) diberikan sebanyak 3 kali dengan interval 4 minggu dari pemberian sebelumnya. Menurut American Academy of Pediatrics (2013), imunisasi hepatitis B harus diberikan ke semua bayi baru lahir segera setelah lahir sampai 12 jam setelah lahir dan paling telat sampai usia 1 minggu.

Hasil penelitian ini menunjukkan bahwa RS. Kebonjati sudah melaksanakan program pemerintah tentang tata laksana pemberian imunisasi Hepatitis B. Bayi yang lahir dalam kondisi sehat langsung diberikan imunisasi Hepatitis B 0 segera setelah lahir, tetapi pada bayi yang lahir dalam kondisi tidak sehat, pemberian imunisasi HB 0 ditunda sampai keadaan bayi sehat dan diusahakan sebelum bayi berusia 1 minggu. Hal tersebut didukung oleh pendapat American Academy of Pediatrics bahwa imunisasi HB 0 harus diberikan segera pada seluruh bayi baru lahir dan diberikan pada bayi sehat sebelum berusia 1 minggu.

\section{Score Nyeri Sesudah Imunisasi}

Hasil penelitian menunjukkan ada perbedaan yang signifikan dari score nyeri pada bayi sesudah imunisasi Hepatitis B 0 pada kelompok intervensi dibanding kelompok kontrol. Hal ini disebabkan karena pada kelompok intervensi diberikan kompres blue ice sebelum pemberian imunisasi Hepatitis B 0 , sedangkan kelompok kontrol tidak diberikan kompres blue ice sebelum pemberian imunisasi Hepatitis B 0 . Hasil penelitian ini didukung oleh Dewi (2012) menyatakan bahwa terdapat perbedaan yang signifikan dari respon nyeri pada neonatus yang diukur berdasarkan skor NIPS pada prosedur pemasangan infus ( $p$-value 0,000 ). Esfahani et al (2013) merekomendasikan 
penggunaan skala nyeri NIPS pada bayi usia kurang dari 6 bulan yang mendapatkan vaksinasi Hepatitis $B$ dan DPT.

Nyeri merupakan suatu peringatan system saraf perifer terhadap system saraf pusat terhadap adanya cidera atau resiko terjadinya cidera pada tubuh (Movehadi, 2006). Respon nyeri yang dapat muncul pada bayi dapat berupa respon perilaku, respon fisiologi dan respon metabolik. Respon perilaku diperlihatkan bayi dengan gelisah, merintih, dan menangis terus menerus (Wong, Perry, \& Hockenberry, 2004). Respon fisiologi ditandai dengan adanya perubahan signifikan dari denyut jantung, tekanan darah (meningkat atau menurun), peningkatan tekanan intra kranial, tonus vagal, frekuensi pernafasan dan saturasi oksigen (Franck \& Gregory, 1993 dalam Wong, Perry, \& Hockenberry, 2004). Stimulus nyeri akan merangsang pengeluaran nosiseptor (epineprin, norepineprin, glucagon, kortikosteron, kortisol, laktat, piruvat dan glukosa) (Potter \& Perry, 2006).

Menurut Taddio (2010), nyeri yang tidak ditangani pada masa lalu membuat stress, takut dan kecemasan bahkan berdampak menjadi phobia yang mempengaruhi persepsi nyeri. Oleh karena itu pengolahan nyeri suntikan imunisasi dimasa bayi haruslah menjadi prioritas. Hal ini disebabkan pada usia bayi serabut saraf mielin belum sempurna. Menurut Dambska dan LaureKamionowska (2002 dalam Sarimin, 2012) menjelaskan bahwa setelah lahir usia 7 bulan hingga 15 bulan adalah periode pematangan mielin. Sementara menurut Parazzini et al (2002) dalam Sarimin (2012) mengatakan bahwa pada usia 36-40 bulan mielinisasi sudah lebih matang seperti dewasa. Perkembangan serabut mielin yang belum sempurna inilah yang membuat bayi belum dapat mempersepsikan nyeri yang dirasakan.

\section{Pengaruh Kompres Blue Ice Terhadap Skala Nyeri Pada Bayi Yang Telah Mendapatkan Imunisasi Hepatitis B 0}

Pemberian kompres dingin Blue lce pada bayi yang akan diimunisasi dapat membantu menghilangkan nyeri dengan pelepasan endorphin, sehingga memblok transmisi serabut saraf sensori A-beta yang lebih besar dan lebih cepat. Proses ini menurunkan transmisi nyeri melalui serabut $\mathrm{C}$ dan A-delta berdiameter kecil, sehingga gerbang sinap menutup transmisi impuls nyeri. Menurut teori Gate Control dari Melzack \& Wall (1965), mengatakan bahwa impuls nyeri dapat diatur atau dihambat oleh mekamisme pertahanan disepanjang sistem saraf pusat. Mekanisme pertahanan dapat ditemukan di sel-sel gelatinosa subtansia dalam kornu dorsalis pada medula spinalis menghasilkan endorphin yang akan menghambat transmisi nyeri yang efektifitasnya bisa dipengaruhi oleh stimulasi kutaneus (Smeltzer \& Bare, 2002).

Levine dalam teorinya yang disebut sebagai Levine's conservation (Tomey \& Aligood, 2006) mengatakan prosedur invasif seperti pemberian imunisasi merupakan bagian dari integritas struktural yang akan menyebabkan nyeri sehingga meningkatkan kebutuhan oksigenasi yang dapat mengancam konservasi energi. Selain itu nyeri akan menyebabkan stress yang dapat mengancam integritas personal bayi. Oleh karena diperlukan untuk mencegah terjadinya kerusakan fisik dan meningkatkan proses penyembuhan dan mencegah nyeri. Manajemen nyeri merupakan salah satu tindakan yang dapat digunakan untuk menghemat energi pada bayi.

Menurut pendapat peneliti berdasarkan hasil penelitian yang sudah dilakukan pemberian kompres dingin sangat bermanfaat menurunkan respon nyeri yang dirasakan bayi dan merupakan metoda aman dan mudah mengaplikasikannya.

\section{KESIMPULAN}

Sebagian besar $(69,4 \%)$ responden berusia 0 hari dan sebagian besar responden $(52,8 \%)$ berjenis kelamin laki-laki. Score nyeri sesudah imunisasi Hepatitis B 0 pada kelompok kontrol memiliki nilai 5. Intensitas nyeri sesudah imunisasi Hepatitis B 0 pada kelompok intervensi memiliki nilai 1. Adanya pengaruh pemberian kompres blue ice terhadap skala nyeri pada bayi yang telah mendapatkan imunisasi Hepatitis B 0 dengan p-value 0,00 . 


\section{SARAN}

Hasil penelitian dapat dijadikan sebagian dasar dalam penyusunan kebijakan atau Standar Operasional Prosedur (SOP) penatalaksanaan Imunisasi, yaitu penggunaan kompres blue ice sebagai salah satu prosedur dalam mengurangi nyeri pada bayi sebelum pemberian imunisasi. Dengan adanya kebijakan tersebut, diharapkan perawat dapat menerapkan teknik mengurangi nyeri pada bayi saat di imunisasi.

Hasil penelitian ini semoga dapat memperkaya perkembangan ilmu keperawatan di Indonesia sehingga wawasan dan pengetahuan perawat khususnya perawat pediatrik akan makin berkembang tentang manajemen nyeri non farmakologi. Manajemen nyeri non farmakologi dapat diterapkan oleh institusi pendidikan dengan cara memasukkan materi manajemen nyeri non farmakologi ke dalam silabus atau pokok bahasan kurikulum untuk dipraktekkan di laboratorium dan metode belajar. Dengan demikian diharapkan mahasiswa keperawatan bukan hanya memahami tentang konsep nyeri tetapi dapat menerapkannya dalam kehidupan sehari-hari Hasil penelitian ini juga dapat dijadikan data dasar untuk penelitian selanjutnya

\section{REFERENSI}

Abuelkheir, M., Alsourani, D., Eyadhy, A.A., Temsah, M.H., Meo, S.A., Alzamil, F., (2014). EMLA cream: A pain relieving strategy for childhood vaccination. Journal of International Medical Research. February 27, 2014. http://mdlinx.pdr.net

Aminabadi, N. A., \& Farahani, R.M.Z., (2009). The effect of pre-cooling the injection site on pediatric pain perception during the administration of local anesthesia. March 9, 2014. http://scholar.google.co.id

Andarmoyo, S., (2013). Konsep dan proses keperawatan nyeri. Jogjakarta: Ar-Ruzz Media

Dahlan, S., (2013). Besar sampel dan cara pengambilan sampel dalam penelitian kedokteran dan kesehatan. (Cetakan Kedua). Jakarta: Salemba Medika
Dilli, D., Kucuk, I.G., Dallar, Y. (2009). Intervention to reduce pain during vaccination in infancy. J. Pediatric: PubMed

Esfahani, M.S., Sheykhi, S., Abdeyazdan, Z., Jodakee, M., Boroumandfar, K., (2013). A comparative studi on vaccinatio pain in the methodes of massage and mother breastfeeding during injection of infant refering to Navabsafavi health care senter in Isfanah. Irianan Journal anf Midwifiry Research. February 28, 2014. http://www.ncbi.nlm.nih.gov

Fauzi, I., dan Hendayani, N. (2013). Pengaruh kompres dingin terhadap tingkat nyeri pada prosedur invasif pemasangan infus anak usia sekolah di RSUD Bendan Kota Pekalongan. Pekalongan: Stikes Muhammadiyah Pekajangan

Fikri, R., dan Khusnal, E. (2011). Pengaruh kompres dingin terhadap intensitas nyeri pada bayi saat diimunisasi di Puskesmas Piyungan Bantul. Tesis. Yogjakarta: Stikes Aisyiyah

Gallo. A. M. (2003). The fifth vital sign: implementation of the neonatal infant pain scale. Priciples \& practice (199-121). February 14, 2014. Jognn Principles \& Practice

Grunau, R. E., Whitfield, M. F., Petrie-Thomas, J., Synnes, A. R., Cepeda, I. L., Keidar, A. \& Johannesen, D. (2009). Neonatal pain, parenting stress and interaction, in relation to cognitive and motor development at 8 and 18 months in preterm infants. Pain, 143(1-2), 138-146

Hockenberry, M. J., \& Wong, D. (2009). Buku ajar keperawatan pediatrik Wong. (ed.6, vol. 2). Jakarta: EGC

Hockenberry, M. J., \& Wilson, D. (2009). Essensials of pediatrics nursing. (8th ed.). St Louis: Mosby Elsevier

James, S.R. \& Ashwill, J.W., (2007). Nursing care of children, principles \& practice. (3th edition). St, Louis: Saonders Elsvier

Kenner \& Mcgart, (2004). Developmental care of newborns \& infants: A guide for health professionals. USA: Elsevier 
Kolcaba, K \& Dimarco, (2005). Comfort theory and is applicationto pediatric nursing, Pediatric Nursing, 31(3), 187-94

Malarvizhi, G., Vasta, M., Roseline, M., Nithin, S., \& Paul, S., (2012). Interrater reliability of neonatal infant pain scale as multidimentional behavioral pain tool. Nitte university of journal of health science 2012, 26-30. May 18, 2013

Movahedi, A.F., Rostami, S., Salsali, M., Keikhaee, B., \& Moradi, A. (2006). Effect of local refrigeration prior to venipuncture on pain related responses in school age children. Australian Journal of advanced nursing. 24(2), 51-55

Neil, (2007). Pain reduction during pediatric immunization: Evidence Based Review and recomemmendation. American Academy of Pediatrics. February 14, 2014.

http://pediatrics.aappublications.org

Polit, D.F., \& Beck, C.T. (2008). Nursing research: Generating and assesing evidence for nursing practice. Philadelphia: Lippincott

Proverawati \& Andini, (2010). Imunisasi dan vaksinasi. Yogyakarta : Nuha Medika

Ranuh, I. G. N., Suyitno, H., Hadinegoro, s. R. Kartasasmita, C. B. (2011). Pedoman
Imunisasi Di Indonesia. Jakarta : Satgas Imunisasi IDAI

Ronald, (2009). Management of pediatric pain and distress due to medical procedures. Chapter 11. in Handbook of Pediatric Psychology. (4th edition). New York: The Guilford Pres

Sulistyani, (2009). Pengaruh pemberian kompres es batu terhadap tingkat nyeri pada anak usia pra sekolah yang dilakukan prosedur pemasangan infus di RSCM. Tesis. Jakarta : Magister Keperawatan UI

Taddio, A., Chambers, et al. (2010.). Clinical practice guideline: Reducing the pain of childhood vaccination: an evidencebased clinical practice guideline. Canadian Medical Association. January 25, 2014

Tamsuri, A., (2007). Konsep dan penatalaksanaan nyeri. Jakarta: EGC

Twycross, A.,. (2006). Managing pain reducing the fist year of life. Infant (vol.2 issue 1) February 14, 2014. http://www.infantgrapevine.co.uk

Yurdanur, D., (2012). Non pharmacological therapies in pain management. Abant Izzet Baysal University, Bolu Health Sciences High School, Turkey. May 13, 2014. CINHL (Ebsco Host) database. 